\title{
Clinicopathological predictive factors for ipsilateral and contralateral events following initial surgery to treat ductal carcinoma in situ
}

\author{
Nobuko Tamura $\cdot$ Hitoshi Tsuda $\cdot$ Masayuki Yoshida $\cdot$ \\ Takashi Hojo $\cdot$ Sadako Akashi-Tanaka $\cdot$ \\ Takayuki Kinoshita $\cdot$ Kenichi Sugihara
}

Received: 14 June 2014 / Accepted: 28 January 2015/Published online: 11 February 2015

(C) The Author(s) 2015. This article is published with open access at Springerlink.com

\begin{abstract}
Background Ipsilateral breast tumor recurrence (IBTR) after partial breast resection and contralateral breast tumor recurrence (CBTR) have been shown to occur relatively frequently in patients with ductal carcinoma in situ (DCIS). However, there is only limited data from Japanese institutes to support this.

Methods Of 301 consecutive DCIS patients, 179 patients underwent a mastectomy, and the other 122 underwent partial resection in the National Cancer Center Hospital, Tokyo, with a median follow-up period of 2,106 days. We reviewed clinicopathological parameters including age, menopausal status, body mass index, family history (FH) of breast cancer, tumor size, histological subtype, nuclear
\end{abstract}

\author{
N. Tamura \\ Department of Breast and Endocrine Surgery, Toranomon \\ Hospital, Tokyo, Japan \\ N. Tamura $\cdot$ H. Tsuda $\cdot$ M. Yoshida \\ Department of Pathology and Clinical Laboratories, National \\ Cancer Center Hospital, Tokyo, Japan \\ N. Tamura $\cdot$ K. Sugihara \\ Surgical Oncology Division, Tokyo Medical and Dental \\ University, Tokyo, Japan \\ H. Tsuda $(\bowtie)$ \\ Department of Basic Pathology, National Defense Medical \\ College, Namiki 3-2, Tokorozawa, Saitama 359-8513, Japan \\ e-mail: hstsuda@gmail.com \\ T. Hojo - T. Kinoshita \\ Breast Surgery Division, National Cancer Center Hospital, \\ Tokyo, Japan \\ S. Akashi-Tanaka \\ Division of breast Surgical Oncology, Showa University School \\ of Medicine, Tokyo, Japan
}

grade (NG), hormone receptor (HR) and human epidermal growth factor receptor 2 (HER2) status, treatment, and the surgical margin status of partially resected specimens. The risk associated with each of these parameters for IBTR in 122 patients who underwent partial resections, and for CBTR in a total of 301 patients were calculated using Cox proportional hazard general linear models.

Results Of the 122 patients who underwent partial breast resection, IBTR occurred in $7(5.7 \%)$. The risk of IBTR was higher or tended to be higher in younger patients or those with lower NG tumors, but did not change significantly with respect to margin status or irradiation. Amongst the entire cohort of 301 patients, CBTR occurred in 18 cases $(6.0 \%)$. CBTR occurred significantly more frequently in patients with a FH of breast cancer and with HR+/HER2 - subtype tumors by univariate analyses, and tumor subtype was an independent risk factor for CBTR by multivariate analysis.

Conclusions The local recurrence rate was low following partial resection of DCIS. Younger age was a risk factor for IBTR, whereas the HR+/HER2- tumor subtype and a FH of breast cancer were risk factors for CBTR.

Keywords Ductal carcinoma in situ (DCIS) - Ispilateral breast tumor recurrence (IBTR) - Contralateral breast tumor recurrence (CBTR) · Histological subtype · Intrinsic subtype $\cdot$ Nuclear grade

\section{Introduction}

The proportion of ductal carcinoma in situ (DCIS) amongst all surgically resected breast cancers is reported to be $20 \%$ in Western countries and nearly $10 \%$ in Japan [1-5]. Pure DCIS in itself is not a life threatening disease, and the local 
recurrences if that appear as DCIS do not influence the overall survival rate of patients. True DCIS will theoretically not metastasize to regional lymph nodes or relapse in a distant organ, and thus the management of DCIS patients focuses on local control of the primary lesion and early detection and treatment of both ispilateral breast tumor recurrence (IBTR) and contralateral breast tumor recurrence (CBTR) [6, 7]. Therefore, it is important to estimate the risk of IBTR and CBTR based on the surgically resected DCIS specimens and the clinical characteristics of patients.

When a partial resection is performed for a patient with DCIS, IBTR may occur even if complete resection is achieved; a previous study found that the 5- and 10-years local recurrence rates were 8.3-9.6 and 12.7-15.4\% when local irradiation was included in treatment, and 16.6-20.7 and 20.0-30.5\% when local irradiation was not included, respectively [8-13]. In Japanese patients, when both invasive carcinoma and DCIS were combined, the 10-year IBTR rates were reported to be $8.5 \%$ after partial resection plus irradiation and $17.2 \%$ after partial resection alone [14]. Positive surgical margins and the absence of local irradiation have been established as significant risk factors for IBTR in DCIS patients treated with partial resection. On the other hand, a 10-year IBTR rate after partial resection for DCIS was reported to be only $3.3 \%$ after surgical therapy alone in a study conducted in a Japanese institute that treated a large number of patients [15].

A mastectomy should prevent IBTR, but CBTR may still occur, with reported 5- and 10-years CBTR rates of 3.3-3.6 and 6.9-7.9\%, respectively [9, 12]. In the National Surgical Adjuvant Breast and Bowel Project (NSABP) B-24 study, CBTR was shown to occur more often in patients with estrogen receptor (ER)-positive DCIS than in those with ER-negative DCIS (8.9 vs. $5.6 \%$ ) [8], suggesting that the expression of hormone receptors (HRs) by DCIS may predict subsequent contralateral breast cancer [16]. However, risk factors for CBTR are not well established in Japanese DCIS patients.

In this study, we examined the IBTR and CBTR rates after surgical therapy for primary DCIS in a cohort of Japanese patients. In order to identify risk factors for IBTR and CBTR, we compared these recurrence rates between subclasses of DCIS with various clinicopathological features.

\section{Patients and methods}

Patients

Of 5,731 consecutive patients who received treatment for primary breast carcinoma in the National Cancer Center
Hospital (NCCH), Tokyo, between 1993 and 2008, 353 patients $(6.1 \%)$ were histologically diagnosed with DCIS. Four patients were excluded from the cohort because clinical, pathological, or immunohistochemical data were not available. Because the purpose of this study included a risk evaluation of CBTR, we also excluded 48 patients who received bilateral total or partial breast resections to synchronous or metachronous bilateral breast cancers: 23 had synchronous bilateral breast cancers, and 25 had past contralateral breast cancer when they underwent surgery to treat the existing DCIS. The pathological diagnoses in the 25 past contralateral breast cancers were invasive ductal carcinoma in 14, DCIS in 7, lobular carcinoma in situ (LCIS) in 2 and unknown in 2 . Only 10 of these 25 patients underwent systemic therapy, which consisted of chemotherapy in 3 cases, endocrine therapy in 1 case, and both chemotherapy and endocrine therapy in 1 case. The type of systemic therapy used for the remaining 5 patients is unknown.

Among the remaining 301 patients, partial breast resections (lumpectomy or quadrantectomy) and total mastectomies were initially performed in 173 cases and 128 cases, respectively. For all cases in which partial resection was considered, intraoperative frozen section diagnosis of surgical margins were performed. When the margins were tumor-positive, additional resections were performed until the margins were shown to be negative. In 38 patients, the planned operation was changed from a partial resection to a total mastectomy because of a positive surgical margin. Whole, surgically resected specimens were cut into tissue blocks and processed to give permanent formalin-fixed paraffin-embedded sections. In the remaining 135 patients who finally received partial mastectomy, surgical margins were found to be positive ( $<1 \mathrm{~mm}$ from the tumor) in the permanent sections from 48 patients. Of these, 13 patients chose to undergo a subsequent total mastectomy, 12 patients underwent an additional partial resection, where surgical margins turned out to be negative $(1 \mathrm{~mm}$ or more from the tumor), 17 patients underwent radiotherapy without additional breast resection; and 6 patients refused an additional resection or irradiation. Thus in total, 122 patients underwent a partial mastectomy (of whom 95 were treated using irradiation to the residual ipsilateral breast), and 179 patients underwent a total mastectomy.

Ninety-one patients underwent axillary lymph node dissection, and 124 patients underwent sentinel node biopsies, and lymph node metastasis was not detected in any of these 215 patients. The remaining 86 patients were not assessed using axillary staging. Twenty-six patients also underwent adjuvant systemic endocrine therapy, but the remaining 275 patients were not administered an adjuvant therapy.

The median follow-up time was 2,106 days (range 30-6,530 days). Follow-up was performed every 6 months 
for the first 5 years following surgery, and then every year for a further 5 years. Most patients were examined by tumor palpation, mammography, and ultrasonography. Further diagnostic imaging was performed depending on the symptoms or concerns of the patients. We reviewed the following clinicopathological features of 301 cases using the medical charts: age, menopausal status, body mass index (BMI), family history (FH) of breast cancer, tumor size, and surgical margin status of partially resected specimens. This study was approved by the internal review board of the National Cancer Center.

Histology and immunohistochemistry

Histopathological characteristics of hematoxylin-eosin (HE)-stained slides of the representative cut surface of the main tumor were reviewed by two observers (N.T. and H.T.) with regard to histological subtype and nuclear grade (NG). In 4 cases, histological diagnosis was changed from DCIS to microinvasive carcinoma, with invasion foci $<1.0 \mathrm{~mm}$ in diameter. The histological subtypes of DCIS were classified into 7 groups: comedo, cribriform, solid, papillary, and low papillary according to the predominant histological pattern [17], as well as solid-papillary, flat, and LCIS. The solid-papillary subtype was immunohistochemically confirmed to show neuroendocrine differentiation using anti-synaptophysin and anti-chromogranin A antibodies (Dako, Carpinteria, CA, USA). NG was evaluated according to the criteria of the Consensus Conference Committee [17].

HR expression status, including ER and progesterone receptor (PR), and human epidermal growth factor receptor 2 (HER2) were re-examined immunohistochemically using the representative cut surface of formalin-fixed paraffinembedded tissue sections from each of the 301 tumors. ER and PR were assayed using a mouse anti-ER monoclonal antibody (clone 1D5, Dako) and a mouse anti-PR monoclonal antibody (clone PgR636, Dako), respectively, on a Dako autostainer according to the manufacturer's instructions. HR positivity was evaluated using the Allred score system, and a score of 3 or more was judged as positive, whereas a score of 2 or less was judged as negative [30]. For HER2 detection, the HercepTest (Dako) was used according to the manufacturer's instructions, and a score of $2+$ or 3+ was judged as HER2-positive [31]. The surrogate intrinsic subtype was classified as follows: HR+/HER2-, $\mathrm{HR}+/ \mathrm{HER} 2+$, HR -/HER 2 +, and HR -/HER2-.

\section{Statistical analysis}

The distribution of different parameters between patients was compared using the Chi squared test or Fisher exact test. Age, BMI and tumor size were numerical factors so we tried to decide cut-off values from each mean of distribution. BMI and tumor size showed log-normal distribution, but age cannot showed one peak distribution so we used median. The predictive value of parameters for IBTR and CBTR was calculated using the Cox univariate and multivariate proportional hazard general linear models. For the parameters that included a subgroup with no events, Cox analysis was not performed. The calculation was performed using JMP ${ }^{\circledR} 9.02$ software (SAS 2009).

\section{Results}

Clinicopathological characteristics

The median age of the 301 patients with DCIS was 50 years (range 26-83 years), 164 of these women were premenopausal, and the other 137 were postmenopausal. The median BMI was 21.5 (range 12.8-33.3). Forty-six patients $(15 \%)$ had a $\mathrm{FH}$ of breast cancer, which involved a first degree relative in 17 cases and a second degree or more distant relative in 29 cases. The median tumor size was $2.7 \mathrm{~cm}$ (range $0.1-9.5 \mathrm{~cm}$ ) (Table 1).

Sixty cases $(20 \%)$ were of the comedo subtype, and 241 cases $(80 \%)$ were of the non-comedo subtype. Amongst the former, $94(31 \%)$ were cribriform, 48 (16\%) were solid, $45(15 \%)$ were papillary, $16(5 \%)$ were solid papillary, $28(9 \%)$ were low papillary, and $10(3 \%)$ were LCIS. Both the comedo and non-comedo subtypes (for example cribriform tumors) frequently showed signs of necrosis; the main tumor was necrotic in a total of 72 cases (24\%), 60 of which were the comedo subtype and 12 were the cribriform subtype. The NG was 1 in 181 tumors (60\%), 2 in 56 tumors (19\%), and 3 in 64 tumors $(21 \%)$.

The tumors were found to be HR positive in 238 cases (79 \%) and negative in 63 cases (21\%), and tumors were HER2 positive in 57 cases (19\%) and negative in 244 cases (81\%). HR+/HER2 - , HR+/HER2+, HR-/HER2+, and HR-/HER2 - tumors were found in 222 (74\%), 12 (4\%), $45(15 \%)$, and 22 cases ( $7 \%)$, respectively.

HR-tumor positivity was significantly associated with age 40 years or younger (90 vs. $77 \%$ in the reference, $p=0.04$ ), premenopausal status (89 vs. $67 \%$ in the reference, $p<0.0001)$, smaller tumor size $(<1.3 \mathrm{~cm})$ (88 vs. $76 \%$ in the reference, $p=0.03)$, non-comedo subtype tumor ( 88 vs. $43 \%$ in the reference, $p<0.0001$ ), absence of necrosis (90 vs. $44 \%$ in the reference, $p<0.0001$ ), and lower NG (NG1) (93 vs. $58 \%$ in the reference, $p<0.0001)$. In contrast, HER2 status was associated or tended to be associated with postmenopausal status (23 vs. $15 \%$ in the reference, $p=0.07)$, larger tumor size $(1.3 \mathrm{~cm}$ or larger) (21 vs. $12 \%$ in the reference, $p=0.08$ ), comedo subtype tumors (55 vs. $10 \%$ in the reference, $p<0.0001$ ), 
Table 1 Clinicopathological characteristics of 301 ductal carcinoma in situ cases

\begin{tabular}{|c|c|}
\hline Parameter & Number of cases $(\%)$ \\
\hline Median age (range) (years) & $50(26-83)$ \\
\hline \multicolumn{2}{|l|}{ Menopausal status } \\
\hline Premenopausal & $164(54)$ \\
\hline Postmenopausal & $137(46)$ \\
\hline Median body mass index (range) & $21.5(12.8-33.3)$ \\
\hline \multicolumn{2}{|l|}{ Family history } \\
\hline No & $255(85)$ \\
\hline Yes & $46(15)$ \\
\hline 1st degree & $17(6)$ \\
\hline 2nd degree & $27(8)$ \\
\hline Unknown & $2(1)$ \\
\hline Median tumor size (range) $(\mathrm{cm})$ & $2.7(0.1-9.5)$ \\
\hline \multicolumn{2}{|l|}{ Histological subtype } \\
\hline Comedo & $60(20)$ \\
\hline Non comedo & $241(80)$ \\
\hline Cribriform & $94(31)$ \\
\hline Solid & $48(16)$ \\
\hline Papillary & $45(15)$ \\
\hline Solid papillary & $16(5)$ \\
\hline Low papillary & $28(9)$ \\
\hline Lobular in situ & $10(3)$ \\
\hline \multicolumn{2}{|l|}{ Necrosis } \\
\hline Positive & $72(24)$ \\
\hline Negative & $229(76)$ \\
\hline \multicolumn{2}{|l|}{ NG } \\
\hline NG1 & $181(60)$ \\
\hline NG2 & $56(19)$ \\
\hline NG3 & $64(21)$ \\
\hline \multicolumn{2}{|l|}{ HR status } \\
\hline Positive & $238(79)$ \\
\hline Negative & $63(21)$ \\
\hline \multicolumn{2}{|l|}{ HER2 } \\
\hline Score 0 or $1+$ & $244(81)$ \\
\hline Score $3+$ or $2+$ & $57(19)$ \\
\hline \multicolumn{2}{|c|}{ Surrogate intrinsic subtype (HR/HER2) } \\
\hline $\mathrm{HR}+/ \mathrm{HER} 2-$ & $222(74)$ \\
\hline $\mathrm{HR}+/ \mathrm{HER} 2+$ & $12(4)$ \\
\hline HR-/HER $2+$ & $45(15)$ \\
\hline HR-/HER2- & $22(7)$ \\
\hline \multicolumn{2}{|l|}{ Treatment } \\
\hline \multicolumn{2}{|l|}{ Local treatment } \\
\hline Total mastectomy & $179(59)$ \\
\hline Lumpectomy & $122(41)$ \\
\hline Lumpectomy + irradiation & $95(32)$ \\
\hline Lumpectomy only & $27(9)$ \\
\hline \multicolumn{2}{|l|}{ Surgical margin status } \\
\hline Negative & 99 (33) \\
\hline
\end{tabular}

Table 1 continued

\begin{tabular}{ll}
\hline Parameter & Number of cases $(\%)$ \\
\hline Positive & $23(7)$ \\
Systemic treatment & \\
Tamoxifen only & $26(10)$ \\
None & $275(90)$
\end{tabular}

$H E R 2$ human epidermal growth factor receptor $2, H R$ hormone receptor, $N G$ nuclear grade

presence of necrosis (50 vs. $9 \%$ in the reference, $p<0.0001$ ), and higher NG (NG2 or NG3) (38 vs. $6 \%$ in the reference, $p<0.0001$ ) (Table 2).

\section{Prognosis of DCIS}

Amongst the 122 patients who underwent lumpectomy, 7 $(5.7 \%)$ suffered IBTR. The period between surgery and the diagnosis of IBTR in these 7 cases were 431, 799, 1,066, 1,298, 1440, 1960 and 4,054 days (median 1,575 days). Recurrent lesions were invasive ductal carcinoma in 3 cases, mucinous carcinoma in 2 cases, and DCIS in 2 cases. In 2 patients who were found to have a positive surgical margin during resection of DCIS and subsequently experienced IBTR, it was not determined whether these locally relapsed lesions were true recurrences or a secondary primary tumor. The IBTR rate was higher or tended to be higher in patients aged 40 years or younger [hazard ratio, 7.2 compared to the reference, using Cox univariate analysis, $95 \%$ confidence interval (CI), 1.3-40.2, $p=0.03]$ and in those with lower NG (NG1) $(8$ vs. $0 \%$ in the reference, $p=0.06$ by Fisher exact test). A lack of radiotherapy and a positive surgical margin were not significantly associated with IBTR (6 vs. $4 \%$ in the reference, $p=0.7$; and 9 vs. $5 \%$ in the reference, $p=0.8$, respectively) (Table 3 ). Because the only significant risk factor for IBTR in the univariate analyses was younger age, multivariate analyses were not preformed.

Amongst all 301 cases, CBTR occurred in 18 cases $(6.0 \%), 12$ of which involved invasive ductal carcinomas and 6 involved DCIS. The median period of CBTR among these 18 cases was 2,579 days (range 1,206-5,182 days), after surgery for DCIS. The CBTR rate was higher or tended to be higher in patients with a FH of breast cancer (hazard ratio 3.0 by Cox univariate analysis; $95 \%$ CI $1.0-7.9 ; p=0.05$ ), HR-positivity (7.6 vs. $0 \%$ in the reference, $p=0.003$ by Fisher exact test), and HR+/HER2subtype tumors (hazard ratio, 5.6 by Cox univariate analysis; $95 \%$ CI 1.1-101; $p=0.03$ ) (Table 4). An HR+l HER2 - tumor was an independent risk factor for CBTR on multivariate analysis (hazard ratio 5.1; $95 \%$ CI 1.0-92.6; $p=0.04)$ (Table 5). 
Table 2 Relationship between hormone receptor and HER2 status and the clinicopathological characteristics of ductal carcinoma in situ patients

\begin{tabular}{|c|c|c|c|c|c|}
\hline Parameter & Total cases & No. of cases (\%) HR-positive & $p$ & No. of cases (\%) HER2-positive & $p$ \\
\hline \multicolumn{6}{|l|}{ 1. Age (years) } \\
\hline$\leq 40$ & 41 & $37(90)$ & \multirow[t]{2}{*}{0.04} & $7(17)$ & \multirow[t]{2}{*}{0.74} \\
\hline$>40$ & 260 & $201(77)$ & & $50(19)$ & \\
\hline \multicolumn{6}{|c|}{ 2. Menopausal status } \\
\hline Premenopausal & 164 & $146(89)$ & \multirow[t]{2}{*}{$<0.0001$} & $25(15)$ & \multirow[t]{2}{*}{0.07} \\
\hline Postmenopausal & 137 & $92(67)$ & & $32(23)$ & \\
\hline \multicolumn{6}{|c|}{ 3. Body mass index } \\
\hline$\geq 22$ & 132 & $108(82)$ & \multirow[t]{2}{*}{0.27} & $23(17)$ & \multirow[t]{2}{*}{0.52} \\
\hline$<22$ & 167 & $128(77)$ & & $34(20)$ & \\
\hline \multicolumn{6}{|l|}{ 4. Family history } \\
\hline Yes & 46 & $40(87)$ & \multirow[t]{2}{*}{0.13} & $6(13)$ & \multirow[t]{2}{*}{0.25} \\
\hline No & 255 & $198(77)$ & & $51(20)$ & \\
\hline \multicolumn{6}{|c|}{ 5. Tumor size $(\mathrm{cm})$} \\
\hline$<1.3$ & 73 & $64(88)$ & \multirow[t]{2}{*}{0.03} & $9(12)$ & \multirow[t]{2}{*}{0.08} \\
\hline$\geq 1.3$ & 228 & $174(76)$ & & $48(21)$ & \\
\hline \multicolumn{6}{|c|}{ 6. Microinvasion by review } \\
\hline No & 297 & $235(79)$ & \multirow[t]{2}{*}{0.84} & $57(19)$ & \multirow[t]{2}{*}{0.19} \\
\hline Yes & 4 & $3(75)$ & & $0(0)$ & \\
\hline \multicolumn{6}{|c|}{ 7. Histological subtype } \\
\hline Non-comedo & 241 & $212(88)$ & \multirow[t]{2}{*}{$<0.0001$} & $25(10)$ & \multirow[t]{2}{*}{$<0.0001$} \\
\hline Comedo & 60 & $26(43)$ & & $33(55)$ & \\
\hline \multicolumn{6}{|l|}{ 8. Necrosis } \\
\hline Negative & 229 & $206(90)$ & \multirow[t]{2}{*}{$<0.0001$} & $21(9)$ & \multirow[t]{2}{*}{$<0.0001$} \\
\hline Positive & 72 & $32(44)$ & & $36(50)$ & \\
\hline \multicolumn{6}{|l|}{ 9. NG } \\
\hline NG1 & 181 & $159(93)$ & \multirow[t]{2}{*}{$<0.0001$} & $11(6)$ & \multirow[t]{2}{*}{$<0.0001$} \\
\hline NG2, NG3 & 120 & $69(58)$ & & $46(38)$ & \\
\hline
\end{tabular}

$H E R 2$ human epidermal growth factor $2, H R$ hormone receptor, $N G$ nuclear grade

\section{Discussion}

Due to the development of a nationwide screening program using imaging and needle biopsy techniques, the age-adjusted incidence of DCIS has increased 1.5 fold over the last 20 years [based on the data of the Surveillance, Epidemiology, and End Result Program (SEER) of the National Cancer Institute] [1]. Because DCIS is a precursor of invasive and potentially metastatic disease, understanding the relationship between clinicopathological characteristics and prognosis would help to clarify the natural history of cancer development and to establish methods for the secondary prevention of invasive breast cancer.

IBTR has been shown to be relatively common after breast-conserving therapy for DCIS, and the identification of risk factors for IBTR has been considered an important goal. In a meta-analysis, a comedo subtype tumor, necrosis, positive margin status, high tumor grade, and larger tumor size were significant risk factors for IBTR, and several studies showed that HR-HER2+ tumors might also be a risk factor [18, 19]. Available risk evaluation systems for local recurrence after partial resection for DCIS are the Van Nuys prognostic index (VNPI) and the multigene assay. In VNPI, risk is based on tumor size, necrosis, margin status, and age, with the latter being the only host factor [7, 20-22]. A multigene assay for DCIS can also identify DCIS patients with a higher risk of IBTR [23-25].

Our findings differ from those reported by a Japanese large-volume center, in which the IBTR rate after partial resection for DCIS without irradiation was very low, with a 10-year IBTR rate of only $3.3 \%$ [15]. We found that the IBTR rate of patients who underwent partial resection for DCIS was $5.6 \%$. Ninety-nine of the 122 patients who underwent partial resection were found to have negative surgical margins by both intraoperative and permanent histological examinations. When intraoperative frozen section diagnosis revealed a positive surgical margin, additional resections were performed, and if this failed to give a negative margin $(n=23)$, irradiation was usually also performed $(n=19)$. 
Table 3 Cox univariate analyses to estimate the risk of clinicopathological parameters for IBTR amongst ductal carcinoma in situ patients who underwent lumpectomy
CI confidence interval, HER2 human epidermal growth factor receptor 2, $H R$ hormone receptor, IBTR ipsilateral breast tumor recurrence, $N E$ not evaluable, $N G$ nuclear grade

* The $p$ value for differences in NG was calculated using Fisher's exact test because no event occurred in the NG2/NG3 group

\begin{tabular}{|c|c|c|c|c|c|}
\hline \multirow{3}{*}{ Parameter } & \multicolumn{5}{|c|}{ Lumpectomy in 122 cases } \\
\hline & \multirow[t]{2}{*}{ Total } & \multicolumn{4}{|c|}{$\operatorname{IBTR}(\mathrm{n}=7)$} \\
\hline & & No. $(\%)$ & $p$ & Hazard ratio & $95 \% \mathrm{CI}$ \\
\hline \multicolumn{6}{|l|}{ 1. Age (years) } \\
\hline$\leq 40$ & 19 & $3(16)$ & 0.03 & 7.2 & $1.3-40.2$ \\
\hline$>40$ & 103 & $4(4)$ & & & \\
\hline \multicolumn{6}{|c|}{ 2. Menopausal status } \\
\hline Post & 51 & $2(4)$ & 0.4 & & \\
\hline Pre & 71 & $5(7)$ & & & \\
\hline \multicolumn{6}{|c|}{ 3. Body mass index } \\
\hline$\geq 22$ & 58 & $2(3)$ & 0.26 & & \\
\hline$<22$ & 63 & $5(8)$ & & & \\
\hline \multicolumn{6}{|l|}{ 4. Family history } \\
\hline No & 104 & $7(7)$ & $0.1^{*}$ & NE & $\mathrm{NE}$ \\
\hline Yes & 18 & $0(0)$ & & & \\
\hline \multicolumn{6}{|c|}{ 5. Tumor size $(\mathrm{cm})$} \\
\hline$\geq 1.3$ & 67 & $5(7)$ & 0.35 & & \\
\hline$<1.3$ & 55 & $2(4)$ & & & \\
\hline \multicolumn{6}{|c|}{ 6. Histological subtype } \\
\hline Non-comedo & 107 & $5(5)$ & 0.17 & & \\
\hline Comedo & 15 & $2(13)$ & & & \\
\hline \multicolumn{6}{|l|}{ 7. Necrosis } \\
\hline Negative & 22 & $1(5)$ & 0.9 & & \\
\hline Positive & 100 & $6(6)$ & & & \\
\hline \multicolumn{6}{|l|}{ 8. NG } \\
\hline NG1 & 83 & $7(8)$ & $0.06^{*}$ & NE & $\mathrm{NE}$ \\
\hline NG2 & 18 & $0(0)$ & & & \\
\hline NG3 & 21 & $0(0)$ & & & \\
\hline \multicolumn{6}{|l|}{ 9. HR status } \\
\hline Negative & 20 & $1(5)$ & 0.98 & & \\
\hline Positive & 102 & $6(6)$ & & & \\
\hline \multicolumn{6}{|c|}{ 10. HER2 staining } \\
\hline $3+$ or $2+$ & 14 & $0(0)$ & 0.2 & & \\
\hline 0 or $1+$ & 108 & $7(6)$ & & & \\
\hline
\end{tabular}

11. Surrogate intrinsic subtype

$\begin{array}{llll}\text { HR+/HER2- } & 97 & 6(6) & 0.8 \\ \text { Others } & 25 & 1(4) & \end{array}$

12. Adjuvant endocrine therapy

$\begin{array}{lll}\text { Not administered } & 101 & 6(6) \\ \text { Administered } & 21 & 1(5)\end{array}$

13. Irradiation

$\begin{array}{llll}\text { Administered } & 95 & 6(6) & 0.7 \\ \text { Not administered } & 27 & 1(4) & \\ \text { Surgical margin } & & & \\ \text { Positive } & 23 & 2(9) & 0.8 \\ \text { Negative } & 99 & 5(5) & \end{array}$


Table 4 Cox univariate

analyses to estimate the risk of clinicopathological parameters for CBTR in ductal carcinoma in situ patients

CBTR contralateral breast tumor recurrence, $C I$ confidence interval, HER2 human epidermal growth factor receptor $2, H R$ hormone receptor, $N E$ not evaluable, $N G$ nuclear grade

* The $p$ value for difference in HR status was calculated using Fisher's exact test because no event occurred in the HRnegative group

\begin{tabular}{|c|c|c|c|c|c|}
\hline \multirow[t]{2}{*}{ Parameter } & \multirow{2}{*}{$\begin{array}{l}\text { Total } \\
(\mathrm{n}=301)\end{array}$} & \multicolumn{4}{|c|}{$\operatorname{CBTR}(\mathrm{n}=18)$} \\
\hline & & $\begin{array}{l}\text { No. of cases } \\
(\%)\end{array}$ & $p$ & Hazard ratio & $95 \% \mathrm{CI}$ \\
\hline \multicolumn{6}{|l|}{ 1. Age (years) } \\
\hline$\leq 40$ & 41 & $3(7.3)$ & 0.35 & & \\
\hline$>40$ & 260 & $15(5.8)$ & & & \\
\hline \multicolumn{6}{|l|}{ 2. Menopausal status } \\
\hline Pre & 164 & $12(7.3)$ & 0.45 & & \\
\hline Post & 137 & $6(4.4)$ & & & \\
\hline \multicolumn{6}{|l|}{ 3. Body mass index } \\
\hline$\geq 22$ & 132 & $10(7.6)$ & 0.14 & & \\
\hline$<22$ & 167 & $8(4.8)$ & & & \\
\hline \multicolumn{6}{|l|}{ 4. Family history } \\
\hline Yes & 46 & $6(13.0)$ & 0.05 & 3.0 & $1.0-7.9$ \\
\hline No & 255 & $12(4.7)$ & & & \\
\hline \multicolumn{6}{|l|}{ 5. Tumor size $(\mathrm{cm})$} \\
\hline$\geq 1.3$ & 228 & $16(7.0)$ & 0.3 & & \\
\hline$<1.3$ & 73 & $2(2.7)$ & & & \\
\hline \multicolumn{6}{|l|}{ 6.Microinvasion } \\
\hline No & 297 & $17(5.7)$ & 0.14 & & \\
\hline Yes & 4 & $1(25.0)$ & & & \\
\hline \multicolumn{6}{|c|}{ 7. Histological subtype } \\
\hline Non-comedo & 241 & $15(6.2)$ & 0.8 & & \\
\hline Comedo & 60 & $3(5.0)$ & & & \\
\hline \multicolumn{6}{|l|}{ 8. Necrosis } \\
\hline Negative & 229 & $14(6.1)$ & 0.77 & & \\
\hline Positive & 72 & $4(5.6)$ & & & \\
\hline \multicolumn{6}{|l|}{ 9. NG } \\
\hline NG1 & 181 & $14(7.7)$ & 0.31 & & \\
\hline NG2 & 56 & $2(3.6)$ & & & \\
\hline NG3 & 64 & $2(3.1)$ & & & \\
\hline \multicolumn{6}{|l|}{ 10. HR status } \\
\hline Positive & 238 & $18(7.6)$ & $0.003 *$ & $\mathrm{NE}$ & $\mathrm{NE}$ \\
\hline Negative & 63 & $0(0)$ & & & \\
\hline \multicolumn{6}{|l|}{ 11. HER2 staining } \\
\hline 0 or $1+$ & 244 & $17(7.0)$ & 0.16 & & \\
\hline $3+$ or $2+$ & 57 & $1(1.8)$ & & & \\
\hline \multicolumn{6}{|l|}{ 12.Surrogate } \\
\hline \multicolumn{6}{|l|}{ intrinsic subtype } \\
\hline HR+/HER2- & 222 & $17(7.7)$ & 0.03 & 5.6 & $1.1-101$ \\
\hline Others & 79 & $1(1.3)$ & & & \\
\hline \multicolumn{6}{|c|}{ 13. Adjuvant endocrine therapy } \\
\hline Administered & 26 & $1(3.9)$ & 0.78 & & \\
\hline Not administered & 275 & $17(6.2)$ & & & \\
\hline \multicolumn{6}{|c|}{ 14. Irradiation to the conserved breast } \\
\hline Administered & 95 & $4(4.2)$ & 0.51 & & \\
\hline Not administered & 206 & $14(6.8)$ & & & \\
\hline
\end{tabular}


Table 5 Cox multivariate analysis to identify clinicopathological parameters that are independent risk factors for CBTR in ductal carcinoma in situ patients

\begin{tabular}{|c|c|c|c|c|c|}
\hline \multirow[t]{2}{*}{ Parameter } & \multirow[t]{2}{*}{ Total $(n=301)$} & \multicolumn{4}{|l|}{$\operatorname{CBTR}(n=18)$} \\
\hline & & No. of cases $(\%)$ & $p$ & Hazard ratio & $95 \% \mathrm{CI}$ \\
\hline \multicolumn{6}{|c|}{ Surrogate intrinsic subtype } \\
\hline HR +/HER2- & 222 & $17(7.7)$ & 0.04 & 5.1 & $1.0-92.6$ \\
\hline Others & 79 & $1(1.3)$ & & & \\
\hline \multicolumn{6}{|l|}{ Family history } \\
\hline Yes & 46 & $6(13.0)$ & 0.07 & 2.7 & $0.9-7.2$ \\
\hline No & 255 & $12(4.7)$ & & & \\
\hline
\end{tabular}

$C B T R$ contralateral breast tumor recurrence, $H E R 2$ human epidermal growth factor receptor $2, H R$ hormone receptor, $C I$ confidence interval

In the present study, an age of 40 years or younger and a lower NG were significant or nearly significant risk factors for IBTR by univariate analyses, whereas irradiation, surgical margin status, and tumor size were not significant risk factors for IBTR. Amongst patients treated at the NCCH, the low incidence of IBTR was probably due to the detailed histological examination of surgical margins, and the policy of always performing a complete surgical resection when it was possible. Further, multivariate analysis was not possible in this study due to the small number of events.

The identification of clinicopathological parameters that predict the risk of second primary tumors after DCIS might allow the earlier detection of CBTR. In this study, we found that $\mathrm{HR}+$ and HR+/HER2 - tumors, and a FH of breast cancer were significant risk factors for CBTR, and that a HR+/HER2 - tumor was an independent risk factor in a multivariate analysis. These data support the results of other large-scale studies showing that a previous cancer and a FH of breast cancer could predict CBTR, and that non-invasive cancer carried the same level of relative risk for CBTR (8.1 vs. $11 \%$ ) as invasive cancer $[6,26,27]$.

The NSABP B-24 study retrospectively evaluated the relationship between HR status and adjuvant endocrine treatment. In that study, adjuvant tamoxifen significantly reduced both IBTR and CBTR rates amongst ER-positive DCIS patients, but not ER-negative DCIS patients [8]. In addition, CBTR occurred more often in ER-positive DCIS patients than ER-negative DCIS patients (8.9 vs. $5.6 \%$ ), whereas CBTR rates after tamoxifen treatment were the same between these two patient groups [8]. Another study and a review showed that hormonal therapy for ER-positive breast cancer reduced the rates of IBTR and CBTR $[16,28,29]$. On the other hand, another milutcentre retrospective study from Japan showed that the incidence of CBTR per 1000 person-years was 5.1 without endocrine therapy and 3.6 among those with endocrine therapy in pTis and pT1mic patients [32]. Based on the results of the study we report here, HR positivity in DCIS may be a predictor for subsequent CBTR in Japanese patients. These findings justify a further study to clarify if chemoprevention using tamoxifen or an aromatase inhibitor can reduce the occurrence of CBTR in Japanese patients. However, a number of study limitations need to be considered. These are its retrospective nature, the inclusion of patients from only a single institution, and a median follow-up period of less than 10 years.

In conclusion, our findings show that the rate of IBTR in DCIS patients who underwent partial resection was higher in women aged 40 years or younger. HR+/HER2 - tumors and a FH of breast cancer were risk factors for CBTR.

Acknowledgments The authors thank Sachiko Miura, M.T., Chizu Kina, M.T., and Ms. Chinami Onuma for technical assistance. This work was supported in part by the National Cancer Center Research and Development Fund (26-A-4) and by a Grant-in-Aid for Scientific Research from the Ministry of Education, Science, Technology and Culture, Japan.

Conflict of interest The authors declare that they have no conflict of interest.

Open Access This article is distributed under the terms of the Creative Commons Attribution License which permits any use, distribution, and reproduction in any medium, provided the original author(s) and the source are credited.

\section{References}

1. Surveillance, epidemiology, and end results program, National Cancer Institute, http://seer.cancer.gov/.

2. Burstein HJ, Poluak K, Wong JS, Lester SC, Kaelin CM. Ductal carcinoma in situ of the breast. N Engl J Med. 2004;350:1430-41.

3. Nederend J, Duijm LEM, Voogd AC, Groenewoud JH, Jansen $\mathrm{FH}$, Louwman MWJ. Trends in incidence and detection of advanced breast cancer at biennial screening mammography in The Netherlands: a population based study. Breast Cancer Res. 2012;14:R10.

4. Ernster VL, Ballard-Barbash R, Barlow WE, Zheng Y, Weaver DL, Cutter G, et al. Detection of ductal carcinoma in situ in women undergoing screening mammography. J Natl Cancer Inst. 2003;94:1546-54.

5. Cancer Statistics in Japan 2013. Foundation for Promotion of Cancer Research. Tokyo; 2013. 
6. Fisher B, Dignam J, Wolmark N, Wickerham DL, Fisher ER, Mamounas E, et al. Tamoxifen in treatment of intraductal breast cancer: National Surgical Adjuvant Breast and Bowel Project B-24 randomised controlled trial. Lancet. 1999;353:1993-2000.

7. Fisher B, Bryant J, Dignam JJ, Wickerham DL, Mamounas EP, Fisher ER, et al. Tamoxifen, radiation therapy, or both for prevention of ipsilateral breast tumor recurrence after lumpectomy in women with invasive breast cancers of one centimeter or less. J Clin Oncol. 2002;20:4141-9.

8. Allred DC, Anderson SJ, Paik S, Wickerham DL, Nagtegaal ID, Swain SM, et al. Adjuvant tamoxifen reduces subsequent breast cancer in women with estrogen receptor-positive ductal carcinoma in situ: a study based on NSABP protocol B-24. J Clin Oncol. 2012;30:1268-73.

9. Wapnir IL, Dignam JJ, Fisher B, Mamounas EP, Anderson SJ, Julian TB, et al. Long-term outcomes of invasive ipsilateral breast tumor recurrences after lumpectomy in NSABP B-17 and B-24 randomized clinical trials for DCIS. J Natl Cancer Inst. 2011;103:478-88.

10. Correa C, McGale P, Taylor C, Wang Y, Clarke M, Davies C, et al. Overview of the randomized trials of radiotherapy in ductal carcinoma in situ of the breast. J Natl Cancer Inst Monogr. 2010;41:162-77.

11. Cuzick J, Sestak I, Pinder SE, Ellis IO, Forsyth S, Bundred NJ, et al. Effect of tamoxifen and radiotherapy in women with locally excised ductal carcinoma in situ: long-term results from the UK/ ANZ DCIS trial. Lancet Oncol. 2011;12:21-9.

12. Rakovitch E, Nofech-Mozes S, Narod SA, Hanna W, Thiruchelvam D, Saskin R, et al. Can we select individuals with low risk ductal carcinoma in situ (DCIS)? A population-based outcomes analysis. Breast Cancer Res Treat. 2013;138:581-90.

13. Wang SY, Chu H, Shamliyan T, Jalal H, Kuntz KM, Kane RL, et al. Network meta-analysis of margin threshold for women with ductal carcinoma in situ. J Natl Cancer Inst. 2012;104:507-16.

14. Komoike Y, Akiyama F, Iino Y, Ikeda T, Akashi-tanaka S, Ohsumi S, Kusama M, et al. Ipsilateral breast tumor recurrence (IBTR) after breast-conserving treatment for early breast cancer risk factors and impact on distant metastases. Cancer. 2006;106:35-41.

15. Iwamura Y, Horii R, Osako T, Iwase T, Akiyama F. Long-term outcome of ductal carcinoma in situ after surgical intervention. Jpn J Breast Cancer. 2013;28:399-404 (In Japanese).

16. Guerrieri-Gonzaga A, Botteri E, Lazzeroni M, Rotmensz N, Goldhirsch A, Varricchio C, et al. Low-dose tamoxifen in the treatment of breast ductal intraepithelial neoplasia: results of a large observational study. Ann Oncol. 2010;21:949-54.

17. Editorial. Consensus conference on the classification of ductal carcinoma in situ. Cancer. 1997;80:1798-802.

18. Wang S-Y, Shamliyan T, Virnig BA, Kane R. Tumor characteristics as predictors of local recurrence after treatment of ductal carcinoma in situ: a meta-analysis. Breast Cancer Res Treat. 2011;127:1-14

19. Dunne C, Burke JP, Morrow M, Kell MR. Effect of margin status on local recurrence after breast conservation and radiation therapy for ductal carcinoma in situ. J Clin Oncol. 2009;27:1615-20.

20. Silverstein M. The University of Southern California/Van Nuys prognostic index for ductal carcinoma in situ of the breast. Am J Surg. 2003;186:337-43.
21. Altintas S, Toussaint J, Durbecq V, Lambein K, Huizing MT, Larsimont D, et al. Fine tuning of the Van Nuys prognostic index (VNPI) 2003 by integrating the genomic grade index (GGI): new tools for ductal carcinoma in situ (DCIS). Breast J. 2011;17:343-51.

22. Di Saverio S, Catena F, Santini D, Ansaloni L, Fogacci T, Mignani S, et al. 259 Patients with DCIS of the breast applying USC/Van Nuys prognostic index: a retrospective review with long term follow up. Breast Cancer Res Treat. 2008;109:405-16.

23. Solin LJ, Gray R, Baehner FL, Butler SM, Hughes LL, Yoshizawa C, et al. A Multigene expression assay to predict local recurrence risk for ductal carcinoma in situ of the breast. J Natl Cancer Inst. 2013;105:701-10.

24. Liao S, Desouki MM, Gaile DP, Shepherd L, Nowak NJ, Conroy $\mathrm{J}$, et al. Differential copy number aberrations in novel candidate genes associated with progression from in situ to invasive ductal carcinoma of the breast. Genes Chromosom Cancer. 2012;51:1067-78.

25. Muggerud AA, Hallett M, Johnsen H, Kleivi K, Zhou W, Tahmasebpoor S, et al. Molecular diversity in ductal carcinoma in situ (DCIS) and early invasive breast cancer. Mol Oncol. 2010;4:357-68.

26. Ji J, Hemminki K. Risk for contralateral breast cancers in a population covered by mammography: effects of family history, age at diagnosis and histology. Breast Cancer Res Treat. 2007;105:229-36.

27. Reiner AS, John EM, Brooks JD, Lynch CF, Bernstein L, Mellemkjær L, et al. Risk of asynchronous contralateral breast cancer in noncarriers of BRCA1 and BRCA2 mutations with a family history of breast cancer: a report from the Women's Environmental Cancer and Radiation Epidemiology Study. J Clin Oncol. 2013;31:433-9.

28. Staley H, Mccallum I, Bruce J. Postoperative tamoxifen for ductal carcinoma in situ Cochrane systematic review and metaanalysis. Breast. 2014;23:546-51.

29. Nichols HB, Berrington de González A, Lacey JV, Rosenberg PS, Anderson WF. Declining incidence of contralateral breast cancer in the United States from 1975 to 2006. J Clin Oncol. 2011;29:1564-9.

30. Allred DC, Harvey JM, Berardo M, Clark GM. Prognostic and predictive factors in breast cancer by immunohistochemical analysis. Mod Pathol. 1998;11:155-68.

31. Wolff AC, Hammond ME, Hicks DG, Dowsett M, McShane LM, Allison $\mathrm{KH}$, et al. Recommendations for human epidermal growth factor receptor 2 testing in breast cancer: American Society of Clinical Oncology/College of American Pathologists clinical practice guideline update. J Clin Oncol. 2013;31:3997-4013.

32. Aihara T, Tanaka S, Sagara T, Iwata H, Hozumi Y, Takei H, et al. Incidence of contralateral breast cancer in Japanese patients with unilateral minimum-risk primary breast cancer, and the benefits of endocrine therapy and radiotherapy. Breast Cancer. 2014;21(3):284-91. 